\title{
The influence of UGT polymorphisms as biomarkers in solid organ transplantation
}

\author{
Robert Dupuis ${ }^{\mathrm{a},{ }^{,}}$, Andrea Yuen ${ }^{\mathrm{a}}$, and Federico Innocentia,b,c, ${ }^{* *}$ \\ aUniversity of North Carolina at Chapel Hill, Eshelman School of Pharmacy, United States \\ bInstitute for Pharmacogenomics and Individualized Therapy, United States \\ 'Lineberger Comprehensive Cancer Center, United States
}

\section{Abstract}

In solid organ transplant patients, it is important to maintain a fine balance between preventing rejection and reducing adverse effects. Several immunosuppressive agents such tacrolimus, cyclosporine, sirolimus and everolimus require therapeutic drug monitoring. The study of germline variation of the genome has opened novel opportunities to individualize therapy. Among the currently available immunosuppressive agents, cyclosporine, tacrolimus and mycophenolic acid are in vitro substrates of the UGT1A and 2B families of glucuronidation enzymes.

Mycophenolic acid, either given as mycophenolate mofetil or mycophenolate sodium, is the most frequently used antiproliferative immunosuppressant. Mycophenolic acid is a prodrug which is rapidly de-esterified in the gut wall, blood, liver and tissue to the active moiety, mycophenolic acid (MPA). MPA undergoes significant hepatic metabolism to several metabolites. The 7hydroxyglucuronide MPA is the major metabolite and is inactive. This paper reviews the current status of the genetic associations between germline UGT variants and the pharmacokinetics and pharmacodynamics of mycophenolic acid. Our conclusive assessment of the studies conducted so far is that these germline markers are not ready to be used in the clinic to individualize mycophenolic acid dosing and improve outcome. Novel approaches are required to identify new genetic determinants of outcomes in transplantation.

\section{Keywords}

UGT; Transplantation; Toxicity; Rejection; Mycophenolic acid; Pharmacogenetics

\section{Introduction}

In solid organ transplantation, combination immunosuppressive therapy is used for prevention of organ rejection. Several agents such as calcineurin inhibitors (cyclosporine or tacrolimus), mTOR inhibitors (sirolimus or everolimus), antiproliferatives (azathioprine or mycophenolic acid) and corticosteroids are used in combination. Calcineurin inhibitors and antiproliferatives serve as the foundation of this therapy [1].

\footnotetext{
(C) 2012 Elsevier B.V. All rights reserved

*Correspondence to: R. Dupuis, UNC Eshelman School of Pharmacy, 3213 Kerr Hall CB \# 7569, University of North Carolina at Chapel Hill, Chapel Hill, NC 27599-7569, United States. Tel.: +1 919966 6194; fax: +1 919962 0644. re_dupuis@unc.edu (R. Dupuis). ${ }^{* *}$ Correspondence to: F. Innocenti, UNC Institute for Pharmacogenomics and Individualized Therapy, 1093 Genetic Medicine Bldg., CB 7361, 120 Mason Farm Rd., Chapel Hill, NC 27599-7361, United States. Tel.: +1 919966 9422; fax: +1 9199665863. innocent@unc.edu (F. Innocenti)..
} 
These agents are very effective in minimizing organ rejection and maintaining prolonged graft survival. However, they also can produce serious and life threatening toxicities such as nephrotoxicity, neurotoxicity, electrolyte disturbances, hematologic abnormalities and infection. Therefore, it is important to maintain a delicate balance between preventing rejection and minimizing adverse effects. Several of these immunosuppressive agents such tacrolimus, cyclosporine, sirolimus and everolimus require therapeutic drug monitoring. This is due to their narrow therapeutic index, poor correlation between dose and response and toxicity, significant pharmacokinetic inter-and intra-patient variability and changes in these parameters and changes in organ function over time [2].

The study of germline variation of the genome has opened novel opportunities to individualize therapy. Many of the available germline markers that can be used in the clinic relate to genes coding for drug metabolizing enzymes involved in the activation or inactivation of parent drugs [3]. Among those, the UDP-glucuronosyltransferases belong to a superfamily of phase II conjugation enzymes, the genetic variation of which has been extensively studied [4]. Two superfamilies have been described according to sequence homology, UGT1 and UGT2.

As members of the UGT1A and UGT2B families are the only UGTs involved in the metabolism of immunosuppressive agents, we will focus on describing the UGT1A and UGT2B families in this review. The UGT1A proteins are coded from a locus mapping to chromosome 2q37 and spanning more than $218 \mathrm{~kb}$ [4]. The UGT1A gene complex is comprised of 13 unique first exons which undergo alternative splicing with common exons $2-5$. The lead exon at the $5^{\prime}$ end specifies the substrate-binding domain in the aminoterminal region. The common exons at the $3^{\prime}$ end encode the UDP-glucuronic acid-accepting domain. In the UGT1A locus, there are 9 functional enzymes designated as UGT1A1 and UGT1A3-UGT1A10, while UGT1A2p, UGT1A11p, UGT1A12p and UGT1A13p are pseudogenes [5]. The UGT2B enzymes are encoded by separate genes located at 4q13. Each UGT2 gene consists of six exons. Among the various UGT2B isoforms (UGT2B4, UGT2B7, UGT2B28, UGT2B10, UGT2B11, UGT2B15, UGT2B17), UGT2B7 is the enzyme that has been studied the most in pharmacogenetics [6].

Among the currently available immunosuppressive agents, cyclosporine, tacrolimus and mycophenolic acid are in vitro substrates of the UGT1A and 2B families of UGTs. For cyclosporine, glucuronidation is generally considered a minor pathway [7]. Tacrolimus undergoes glucuronidation via UGT1A4 in vitro but the significance of this pathway and its contribution to inter-patient pharmacokinetic variability is not known [8].

Mycophenolic acid, either given as mycophenolate mofetil (MMF) or mycophenolate sodium (EC-MPS), is the most frequently used antiproliferative immunosuppressant. MMF has replaced azathioprine based on major clinical trials indicating improved outcomes compared to azathioprine or placebo [9]. The majority of transplant recipients receive MMF or EC-MPS after transplant [10]. Both agents are similar in terms of pharmacology and adverse effects [11]. The major pharmacologic effect of MPA is inosine monophosphate dehydrogenase (IMPDH) inhibition. The most common adverse effects, which are experienced in at least $30 \%$ of patients, include gastrointestinal and bone marrow toxicities and infection. The majority of clinical pharmacogenetic and pharmacokinetic data have been published with MMF [12].

MMF is a prodrug which is rapidly de-esterified in the gut wall, blood, liver and tissue to the active moiety, mycophenolic acid (MPA). EC-MPS is enteric coated and absorbed as MPA. MPA is metabolized in the gastrointestinal tract and liver via UGTs. MPA undergoes significant hepatic metabolism to several metabolites. The 7-hydroxyglucuronide MPA 
(MPAG) is the major metabolite and is inactive. Two other minor metabolites are produced, the inactive phenolic glucoside and the acyl-glucuronide (AcMPAG), the latter with some pharmacologic and toxicologic effects [13]. These metabolites are excreted via bile into the intestine. MPAG undergoes enterohepatic recirculation via cleavage by bacterial glucuronidases to MPA, which is subsequently reabsorbed back into the systemic circulation. Ultimately, the majority of metabolites are renally eliminated [12].

MPA exhibits significant interpatient pharmacokinetic variability [12]. Several factors are associated with MPA pharmacokinetic variability. These include age, sex, ethnicity, protein binding, liver and renal function as well as drug interactions, time post transplant (affecting the kinetics of MPA due to changes in protein binding and clearance) and the function of drug transporters $[14,15]$.

MPA is typically given as a fixed dose. However, because of the significant pharmacokinetic variability, some studies have shown that total MPA area under the curve (AUC $0-12 \mathrm{~h}$ ) is correlated with outcomes such as early acute rejection $[16,17]$. However, the correlation between total MPA AUC 0-12 h and toxicities is less clear [18]. Recently several randomized studies comparing fixed dose versus concentration-controlled dosing have been conducted with conflicting results $[19,20]$. There is conflicting data as well with trough levels in relation to MPA efficacy and toxicity [14,21]. In addition, trough concentrations are not very good correlates with AUC and their value of therapeutic drug monitoring is debated [22,23].

Unlike the metabolism of other transplant immunosuppressives, glucuronidation plays a significant role in MPA pharmacokinetics. UGTs 1A1, 1A7, 1A8, 1A9 and 1A10 are important for MPA glucuronidation [24,25]. Hepatically-expressed UGT1A9 is responsible for $>50 \%$ of MPA metabolism to MPAG [21]. UGT1A8 and UGT1A10 are predominantly located in the gastrointestinal tract and thought to play a minor role in MPA disposition. MPA is also metabolized via UGT2B7 and UGT1A8, to AcMPAG which may contribute to gastrointestinal and possibly hematologic toxicities [26].

UGT enzyme activity and several single nucleotide polymorphisms (SNPs) have been shown to correlate with changes in protein expression and enzyme catalytic activity [24,2729]. Polymorphisms of these enzymes may have an influence and also contribute to MPA interindividual variation in pharmacokinetics (see Table 1) and pharmacodynamic outcomes (See Table 2).

\section{UGT1A9 and MPA pharmacokinetics}

The majority of studies examining the relationship between UGT polymorphisms and MPA pharmacokinetics have involved UGTIA9 SNPs. These studies have been conducted primarily in kidney transplant recipients. In the first reported study, in a Caucasian population of 95 kidney transplant recipients, who received tacrolimus and steroids, a 50\% reduction in mean total MPA AUC 0-12 h and AUC 6-12 h (day 7 after transplant) was seen in patients who were either carriers of UGT1A9 $-275 \mathrm{~T}>\mathrm{A}$ or $-2152 \mathrm{C}>\mathrm{T}$ or both, compared to noncarriers. This association was seen only in patients on $2 \mathrm{~g} /$ day compared to $1 \mathrm{~g} /$ day doses [16]. It is unclear why this association was seen with MPA dose. Potential reasons for this finding could include differences in intestinal versus hepatic UGT1A9 activity, the influence of other untested UGT SNPs, other SNPs in genes playing a role in MPA disposition, such as those coding for ABC and SLC transporters; the use of tacrolimus which could exhibit dose dependent UGT inhibition; and the effect of renal dysfunction, elevated MPAG concentrations and albumin changes during the early transplant period. This dose effect has not been confirmed by other studies. Also in this study, covariates such as sex, creatinine clearance, and liver dysfunction also influenced the variability in several 
pharmacokinetic parameters. These variables, along with these UGT1A9 SNPs, accounted for $15-43 \%$ of the pharmacokinetic variability in MPA AUC. In a long-term study, conducted over five years, involving 100 Caucasian kidney transplant recipients, the UGT1A9 $-275 \mathrm{~T}>\mathrm{A}$ or $-2152 \mathrm{C}>\mathrm{T}$ SNPs were associated with MPA AUC $0-12 \mathrm{~h}$ below the suggested therapeutic target range. The impact of dose was not examined in this analysis [17]. A smaller study, in 30 Caucasian kidney transplant recipients on tacrolimus, found an association between these same SNPs and MPA AUC 0-12 h. Mean total MPA AUC 0-12 h was $26 \%$ lower in carriers. This association was seen in patients who received doses of $<2 \mathrm{~g} /$ day. This suggests that there may not be a dose effect and that an association between SNP and AUC 0-12 $\mathrm{h}$ could be seen at any dose. Although this requires further validation [30].

Other studies have found associations between these SNPs and MPA pharmacokinetic parameters. However, this association may vary depending on concomitant immunosuppressives such as cyclosporine and tacrolimus or sirolimus in combination with MPA. The largest study to date was conducted in 338 kidney transplant patients, mostly Caucasians, 176 of them were on tacrolimus and 163 on cyclosporine. Carriers of UGT1A9 $-275 \mathrm{~T}>\mathrm{A}$ and $-2152 \mathrm{C}>\mathrm{T}$ who were receiving tacrolimus had a significantly lower MPA AUC 0-12 h (day 3) than non-carriers. However, this effect was not seen for those receiving cyclosporine [31]. In a study of 117 kidney and/or pancreas transplant recipients, either on cyclosporine or tacrolimus without steroids, MPA trough levels (30 days after transplant) were $70 \%$ lower in $-275 \mathrm{~T}>\mathrm{A}$ and $-2152 \mathrm{C}>\mathrm{T}$ carriers in patients on cyclosporine. In contrast to the previous study, there was no significant difference seen in patients on tacrolimus, although the sample size of the patients on tacrolimus was much smaller, making it difficult to draw conclusions about the lack of association in the tacrolimus arm [32]. Troughs, and not AUCs, were evaluated and, as stated earlier, these parameters do not correlate very well with each other. Another consideration in this study is that patients were not receiving steroids, which have been shown to influence the disposition of MPA by reducing AUC exposure [33,34]. In addition cyclosporine interacts with MPA. Cyclosporine can inhibit MRP2, which is responsible for biliary excretion of MPAG and could ultimately affect MPA concentrations and offset any increased UGT1A9 activity [35,36]. Other variables such as renal function, MPA protein binding, and time post-transplant could contribute to these contrasting study results.

Not all studies have found an association between these UGT SNPs and MPA pharmacokinetic variability. In one study, 40 Caucasian kidney transplant patients on cyclosporine without steroids treated with MMF were evaluated at 6 months after transplant. No association was seen with UGT1A9 $-275 \mathrm{~T}>\mathrm{A}$ or $-2152 \mathrm{C}>\mathrm{T}$ and pharmacokinetic parameters [37]. However, this study was not adequately powered to show whether or not a significant association exists.

Picard et al. reported on 115 kidney transplants on cyclosporine and steroids and 70 kidney transplants on sirolimus or tacrolimus and steroids. MPA AUC $0-12 \mathrm{~h}$ was measured between 3 and 6 months after transplant. There was no association seen with the $-275 \mathrm{~T}>\mathrm{A}$ and $-2152 \mathrm{C}>\mathrm{T}$ SNPs and this pharmacokinetic parameter across all groups [38].

Although data is conflicting about the influence of these two SNPs on MPA exposure, some studies as noted above demonstrate a relationship within the first few days after transplant. This may be an important consideration since acute rejection often occurs in the first few days to weeks after transplant. It is also known that MPA exposure is lowest in the early post transplant period. A loading dose approach over the first few days after transplant to overcome this lower exposure has been suggested [21]. Recently, a study in 135 kidney transplant recipients, receiving tacrolimus and steroids, was conducted to examine this approach. The results indicate that an MMF loading dose significantly increased the number 
of patients who achieved a therapeutic MPA AUC $0-12 \mathrm{~h}$ by day 3 compared to those who received a fixed dose without a loading dose. The incidence of adverse effects and acute rejection, although lower, was not statistically different although stated power was not achieved [39]. Unfortunately no genotyping was conducted, but it is worth considering that apriori knowledge of the UGT1A9-275T >A and -2152C $>$ T SNPs, since they are associated with reduced early MPA exposure, could potentially have improved on and impacted these results. Unfortunately, there is no prospective study which has incorporated this early use of genotyping.

Several other UGT1A9 SNPs and their association with MPA pharmacokinetic parameters have also been investigated. Some studies have examined the role of UGT1A9 $-98 \mathrm{~T}>\mathrm{C}$ (UGT1A9*3). This SNP was associated with higher MPA AUC or trough concentrations in patients treated with MMF $[16,31,32,38]$. For example, one study found that carriers had MPA AUC which was $49 \%$ and 54\% higher in patients on tacrolimus and cyclosporine respectively compared to noncarriers [31]. Another study reported a similar finding only in patients who received $1 \mathrm{~g} /$ day and not with $2 \mathrm{~g} /$ day but this was based on only 3 patients with this polymorphism [16]. The frequency of this SNP in these studies and in Caucasians in general is quite low (1.6-3\%) making the interpretation of the genetic associations and its utility difficult [40].

UGT1A9 I399 has also been examined, but no significant associations have been reported $[31,41]$.

UGT1A9 -440C $>\mathrm{T}$ and $-331 \mathrm{~T}>\mathrm{C}$ SNPS have been also evaluated. These are in complete linkage disequilibrium with each other [25]. In one study of 185 kidney transplants, on MMF with either tacrolimus, cyclosporine or sirolimus, $-440 \mathrm{C}>\mathrm{T}$ was associated with a shorter MPA Tmax but with no other pharmacokinetic parameter [38]. However, another study in 40 kidney transplants on cyclosporine demonstrated lower MPA AUC 0-12 h at six months after transplant in patients with either one of the two SNPs. In this study, glomerular filtration rate (GFR) was inversely correlated with MPAG AUC 0-12 h [37]. High MPAG levels can accumulate with reduced GFR, and are known to affect protein binding of MPA, which is highly protein bound [12]. This ultimately can lead to an increase in MPA free fraction, total MPA clearance, and a reduction in MPA AUC. This indirect effect could have significantly influenced the results of this study, questioning the true contribution and association of these SNPs with pharmacokinetic parameters.

Two UGT1A8 SNPs, 830G>A (UGT1A8*3) and 518C >G (UGT1A8*2) have been evaluated for their relationship with MPA pharmacokinetics. Two studies, one in 117 kidney and/or pancreas transplants and the other in 338 kidney transplants found no influence of the 830G >A (UGT1A8*3) SNP on MPA pharmacokinetics. Though these studies had relatively large numbers of patients, few patients (4-7\%) were carriers of these SNPs [31,32]. In the study with 117 kidney and/or pancreas transplants, on MMF plus tacrolimus or cyclosporine without steroids, MPA troughs were $60 \%$ higher in those who were carriers of $518 \mathrm{C}>\mathrm{G}$ (UGT1A8*2). This was seen in tacrolimus patients only. Whereas in the cyclosporine group, troughs were $20 \%$ higher but this association was not significant [32]. In the study of 338 kidney transplants, those receiving cyclosporine with MMF and steroids who were $* 2 / * 2$ had a mean MPA AUC 0-12 h that was $18 \%$ higher than wild-type patients. Those on tacrolimus with MMF and steroids had a 13\% higher mean MPA AUC 0-12 h, but this association was not significant [31]. In contrast to these findings, in a study conducted in 185 recipients with tacrolimus or cyclosporine or sirolimus and steroids, a significantly lower MPA exposure was seen in $* 2 / * 2$ patients, receiving tacrolimus or sirolimus, whereas no impact was seen in the patients on cyclosporine [38]. A study conducted in 72 Japanese patients, treated with tacrolimus and steroids, saw no significant effect of this SNP on MPA 
pharmacokinetics [42]. Therefore, as with other UGT SNPs, conflicting results associated with $518 \mathrm{C}>\mathrm{G}(\mathrm{UGT} 1 \mathrm{~A} 8 * 2)$ have been reported. This could be due to study design issues and other physiologic and pharmacologic parameters that have not been taken into account, as well as other untested UGT SNPs.

\section{UGT2B7 polymorphisms and MPA pharmacokinetics}

UGT2B7 is responsible for the metabolism of MPA to AcMPAG, a minor metabolite. A few studies have reported on the influence of either UGT2B7 -842G>A, $-79 \mathrm{G}>\mathrm{A}$ and $-802 \mathrm{C}>\mathrm{T}$ $(\mathrm{UGT} 2 \mathrm{~B} 7 * 2)$ polymorphisms. These SNPs are in complete linkage disequilibrium with each other. In a study of 40 Caucasian kidney transplants treated with cyclosporine and steroids, MPA AUC 0-12 h was not associated with $-802 \mathrm{C}>\mathrm{T}$ but carriers of this SNP did show a higher MPA maximum concentration [37]. In three other studies, which included either Caucasian, Japanese, or Chinese patients, no association with the $-802 \mathrm{C}>\mathrm{T}$ SNP and MPA pharmacokinetics was reported $[37,42,43]$. In the study including 338 kidney transplants, no influence of $-842 \mathrm{G}>\mathrm{A}$ and $-79 \mathrm{G}>\mathrm{A}$ on MPA pharmacokinetics was reported [31]. These studies, which include both large and small number of patients, indicate that the tested UGT2B7 gene variants have a minor effect on MPA pharmacokinetics.

\section{UGT polymorphisms and MPAG pharmacokinetics}

The major metabolite of MPA is MPAG. Its metabolism is mediated via UGTs 1A1, 1A6, 1A7, 1A8, 1A9 and 1A10, with the most significant contribution from UGT1A9 [40]. A study in 80 Japanese transplant recipients was conducted to evaluate the influence of these SNPs on MPAG pharmacokinetics. MPAG and MPA AUC 0-12 $\mathrm{h}$ and ratio of MPAG/ MPA AUC 0-12 h were measured on day 28 after transplant. There was no association between these UGT1A SNPs and MPAG and MPA AUC 0-12 $\mathrm{h}$ and MPAG/MPA AUC 0$12 \mathrm{~h}$ ratio [44]. In another study which included 40 Caucasian kidney transplants, no association with UGT1A9 polymorphisms was found [37]. Two other studies found similar nonsignificant results between UGT1A9 SNPs and MPAG pharmacokinetics [34,38]. One of these studies by Picard et al. in 185 kidney transplant patients investigated the relationship between MPAG trough, MPAG Cmax and MPAG AUC 0-9 h and UGT1A9 $-275 \mathrm{~T}>\mathrm{A},-2152 \mathrm{C}>\mathrm{T},-440 \mathrm{C}>\mathrm{T} /-331 \mathrm{~T}>\mathrm{C}, 98 \mathrm{C}>\mathrm{T}$ and UGT1A8 $-518 \mathrm{C}>\mathrm{G}$. They did not identify any significant associations [38]. A few studies have evaluated the influence of UGT2B7 SNPs on MPAG AUC and found no association with this pharmacokinetic parameter $[34,37,43]$. Therefore, with the available information, UGT polymorphisms do not seem to play any significant role in MPAG disposition. MPAG variability could be due to other important factors such as transporters and/or renal function.

\section{UGT polymorphisms and AcMPAG pharmacokinetics}

AcMPAG has been thought to contribute to side effects, such as gastrointestinal toxicity and leukopenia, although solid clinical data is lacking [45]. AcMPAG is thought to cause irreversible binding between plasma and tissue proteins and nucleic acids resulting in cellular toxicity. AcMPAG also has proinflammatory activity [13]. AcMPAG, like MPAG, is renally eliminated and concentrations are higher in patients with reduced renal function $[46,47]$. Interindividual variation of AcMPAG concentrations exists, and this could be due, in part, to polymorphisms in UGT2B7 and UGT1A8, the enzymes responsible for the conversion of MPA to AcMPAG. A few studies have evaluated the influence of UGT2B7 SNPs and their association with AcMPAG disposition with conflicting results. One study conducted in 46 Chinese kidney transplants found no association [44]. The other study in 332 kidney transplants (mostly of Caucasian origin) also found no association [48]. In contrast to these studies, two other studies found that there was an influence of UGT2B7 polymorphisms. The first study was conducted in 92 kidney transplants (ethnicity not 
specified) on either cyclosporine, tacrolimus, or sirolimus in combination with MMF, and decreasing steroid doses. Patients were evaluated during the first three months after transplant. This study found that UGT2B7 $-842 \mathrm{G}>\mathrm{A}$ and $-802 \mathrm{C}>\mathrm{T}$, which are in linkage disequilibrium with each other, were associated with higher AcMPAG AUC 0-9 h. This effect was seen only in the sirolimus group and not with cyclosporine or tacrolimus [34]. This association was not seen in the first week but only at 1 and 3 months. Creatinine clearance was reported as not being different among groups. Steroid doses however were higher in the first week, as well as the AcMPAG AUC compared to later times, suggesting an inductive effect on MPA metabolism. This effect would be diminished as steroid dose would be reduced with time. In addition, cyclosporine and tacrolimus could also affect results by altering metabolite transport as drug doses are often reduced over time. As with many studies, the number of patients with their respective genotype was also very small and minimizes the power of this study and its conclusions. Another study was conducted in 68 thoracic, lung or heart transplants mostly of Caucasian origin who received MMF with either cyclosporine or tacrolimus. This study looked at UGT1A9 and UGT2B7 SNPs and MPA and AcMPAG pharmacokinetic parameters as well as outcomes (discussed in later section). They did not find any association between UGT1A9 SNPs and MPA or AcMPAG parameters. They did report that carriers of UGT2B 7 -802T $(* 2)$ demonstrated 2.5-3.7 fold higher AcMPAG AUC 0-12 h and AcMPAG/MPA ratios. Carriers of UGT2B7-138G>A $(* 2 \mathrm{~g})$ had AcMPAG AUC and AcMPAG/MPA ratios that were 9.3-12.3 fold higher than noncarriers [49]. An important consideration is whether or not renal function, which is often altered or reduced in transplant recipients, could have influenced these results. It is known that reduced renal function is associated with the accumulation of the AcMPAG metabolite. The only assessment of renal function in this study was serum creatinine, which was significantly different between heart and lung transplant patients. In addition, serum creatinine in transplant recipients is not always a good estimate of creatinine clearance or glomerular filtration rate. The findings in this study could be the result of altered renal function and metabolite clearance as opposed to UGT2B7 polymorphism or at least this could influence the results. Many centers do not measure MPA concentrations and therefore it would be surprising if AcMPAG concentrations would be measured, being technically more difficult to collect and measure. Although, if more rigorous larger prospective studies could confirm that there is an association with this SNP and ultimately outcomes, knowing the appropriate polymorphisms, in place of specific metabolite concentrations, could prove valuable.

\section{UGT polymorphisms and acute rejection}

The majority of acute rejections are seen within the first year, particularly in the first few months after transplant. Acute rejections vary from b20\% in kidney transplants to approximately $40 \%$ in lung transplants [50,51].

Very few studies (see Table 2) have evaluated acute transplant rejection as a primary outcome in relation to UGT genetic variation. Pharmacodynamic outcomes, such as acute rejection, were often examined as a secondary outcome in most studies. Almost all studies have been conducted in kidney transplant recipients. In a study of 95 Caucasian kidney transplants, receiving tacrolimus and steroids, the relationship between MPA pharmacokinetics and UGT1A9 $-275 \mathrm{~T}>\mathrm{A}$ and $-2152 \mathrm{C}>\mathrm{T}$ was examined and found to be significant. However, they did not see any difference in episodes of biopsy-proven acute rejection (BPAR) in a carriers or noncarriers [16]. In another study of 218 mostly Caucasian kidney transplants, more than $80 \%$ received tacrolimus and steroids and several UGT1A9 and UGT2B7 SNPs were studied. No association between these polymorphisms and BPAR in the first year after transplant was seen [52]. In a large study of 338 kidney transplants, receiving tacrolimus or cyclosporine, the primary outcome measured was MPA AUC in 
kidney transplant patients. UGT1A9 $-275 \mathrm{~T}>\mathrm{A}$ and $-2152 \mathrm{C}>\mathrm{T}$ carriers were found to have a lower MPA AUC (on day 3) among those receiving concomitant tacrolimus. This study further examined any influence on the incidence of BPAR among this subset of patients with acute rejection within 1 year post-transplant. UGT1A9 $-275 \mathrm{~T}>\mathrm{A}$ and/or $-2152 \mathrm{C}>\mathrm{T}$ carriers were at higher risk than noncarriers for having BPAR within 1 year (OR 13.3, 95\% CI 1.096 to $162.279, \mathrm{p}=0.042$ ) after adjustment for age, sex, number of transplantations, donor type, induction therapy, panel-reactive antibodies, number of HLA mismatches, CYP3A5 genotype status, and tacrolimus trough levels [31]. Of note is the extremely wide confidence interval which may be a function of the very small numbers of patients with the variant genotype ( 3 out eight patients) who had rejection. These results are preliminary and a much larger study is required to validate this finding. Similarly, in a study of 68 thoracic transplants, receiving tacrolimus, cyclosporine or sirolimus with steroids, AcMPAG AUC concentrations were compared in relation to UGT2B7 SNPs. Outcomes such as acute rejection were considered secondary measures. An association was seen between these UGT2B7 SNPs and higher AcMPAG exposure. Acute rejection was associated with an AcMPAG AUC $>50 \mu \mathrm{g} \cdot \mathrm{h} / \mathrm{ml}$. The authors found in a multivariate analysis that UGT2B7 SNPs, $-125 \mathrm{C}$ and $-138 \mathrm{~A}$, were significant covariates, along with cyclosporine use for the development of acute rejection. This analysis only included 3 patients with the $-125 \mathrm{C}$ and 4 patients with the -138A SNP [49].

\section{UGT polymorphisms and MPA toxicities}

Gastrointestinal toxicities, such as diarrhea, nausea, vomiting, gastritis and colitis, along with leukopenia, anemia and thrombocytopenia are the most frequently reported side effects of MMF. Infection is also a consequence of MMF use. Dose dependency has been demonstrated mostly for diarrhea and leukopenia. In clinical practice, these side effects often necessitate a dosage reduction or discontinuation of MMF, putting transplant patients at risk for acute organ rejection and graft loss [53].

Several studies have evaluated the association between UGT polymorphisms and adverse effects (see Table 2). Some of these studies are retrospective, and there is a significant heterogeneity in definitions and assessment of adverse effects different regimens, and time after transplant. Two studies examined the effect of UGT polymorphisms on the incidence of diarrhea and other gastrointestinal side effects $[48,49]$. In a study of 332 kidney transplant recipients, van Agteren et al. concluded that the UGT2B7 -840G>A polymorphism did not correlate with either AcMPAG concentrations or the incidence of diarrhea. No association was found between diarrhea that occurred between month 3 and month 12 after transplant and AcMPAG concentrations measured at 3 months [48]. Ting et al., in 68 lung and heart transplant recipients, did not find an association with diarrhea or other reported gastrointestinal side effects and AcMPAG levels or AcMPAG:MPA metabolic ratio, even though UGT2B7 2B7 $-802 \mathrm{C}>\mathrm{T}$ and $-138 \mathrm{~A}(* 2)$ polymorphisms were found to be associated with altered pharmacokinetic profiles [49].

Michelson et al. examined the relationship between UGT2B7 and UGT1A9 polymorphisms and adverse effects one year post-transplantation in 218 kidney transplants, $80 \%$ on tacrolimus with or without steroids. Adverse events were measured as first occurrence of leukopenia, anemia, thrombocytopenia, diarrhea, nausea/vomiting, or infection. No association between UGT1A9 -275T>A, UGT1A9 98T >C, and UGT2B7 802C $>$ T SNPs and adverse events was found [52].

In other studies, diarrhea and gastrointestinal side effects were the outcomes evaluated in relation to UGT polymorphisms [54,55]. Woillard et al. found that non-carriers of UGT1A $8 * 2$ had a 2 -fold higher risk of diarrhea than carriers among 256 renal transplant 
patients. In addition, patients on tacrolimus or sirolimus and MMF had a significantly higher risk of diarrhea, which is not surprising since these side effects are often seen with these agents. Other SNPs examined in this study were UGT1A7 (622C>T), UGT1A8*3 $(830 \mathrm{G}>\mathrm{A})$, UGT1A9 $(-275 \mathrm{~T}>\mathrm{A})$, and UGT2B7 $(-840 \mathrm{G}>\mathrm{A})$. No association between these polymorphisms and gastrointestinal side effects was reported [54]. Also among 67 renal transplant patients, Yang et al. reported that homozygous wild type UGT2B7 -802C > T showed significantly higher mean gastrointestinal symptom rating scale (GSRS) scores compared to variant UGT2B7. Higher diarrhea subscores were also reported among non carriers but this association did not reach statistical significance [55]. In a study, primarily focused on MPA pharmacokinetics and UGT1A9 SNPs, in 133 Caucasian kidney transplants, receiving tacrolimus, admissions due to gastrointestinal symptoms, although a secondary outcome, was reported as higher in carriers of UGT1A9 $-275 \mathrm{~T}>\mathrm{A} /-2152 \mathrm{C}>\mathrm{T}$ [30]. In another study, in which the primary outcome was UGT1A9 SNPs and MPA pharmacokinetics, in 95 kidney transplants, receiving tacrolimus and steroids, a lower incidence of diarrhea was observed in carriers of UGT1A9 $-275 \mathrm{~T}>\mathrm{A} /-2152 \mathrm{C}>\mathrm{T}$ but did not reach statistical significance [16]. The reason for these conflicting results in these two studies is not clear. In a study of 332 renal transplants, no association between leukopenia with AcMPAG concentrations was seen [48]. Betônico et al. found a higher occurrence of infections in the first thirty days after transplant among 74 renal transplant patients receiving MPA $2 \mathrm{~g}$ /day and carrying the UGT1A8 277G>A variant [56]. However, this conclusion in this small retrospective study was based on only 4 patients with this polymorphism. Prausa et al. compared the incidence of UGT polymorphisms between 16 pediatric kidney transplant patients, the majority receiving tacrolimus and steroids, that experienced MMFrelated leukopenia and diarrhea versus 22 pediatric kidney transplants without these adverse effects treated on the same regimen. A greater frequency of these adverse effects was seen in those with UGT1A9 -331T>C SNPs compared to the control group. The study reported that homozygous carriers of UGT1A9 -331T>C experienced leukopenia, but not diarrhea, requiring MMF dosage adjustment [57]. As with other studies the number of patients with a particular variant is very small.

Ting et al. found a significant association between leukopenia and AcMPAG:MPA metabolite ratio $>2$ in a group of 68 thoracic transplants receiving tacrolimus or cyclosporine or sirolimus with steroids. A significantly decreased incidence of leukopenia was seen in UGT1A $-1813 \mathrm{~T}>\mathrm{C}$ carriers. In addition, the occurrence of infection, which was higher, was associated with an AcMPAG AUC $>50 \mu \mathrm{g} \cdot \mathrm{h} / \mathrm{ml}$ and AcMPAG:MPA metabolite ratio $>2$ [49]. Other MPA related side effects including thrombocytopenia and anemia, have also been examined. In this same study, anemia was significantly associated with AcMPAG:MPA>2, and carriers of UGT1A7 Trp208Arg (rs7439366) were found to have a significantly lower incidence of anemia than non carriers [49]. The clinical role of this SNP needs further evaluation. They also reported that patients with higher AcMPAG AUC had a higher occurrence of rejection, infection, leukopenia and anemia. An important consideration with these findings is that anemia and erythropoietin deficiency is commonly seen in transplant recipients and could have been influenced by renal dysfunction and/or other drugs. GFR measurements, for example $<30 \mathrm{ml} / \mathrm{min}$ vs. $>30 \mathrm{ml} / \mathrm{min}$, as opposed to serum creatinine concentrations, which can be an inaccurate reflection of true renal function, and their relationship to elevated AcMPAG levels, should be incorporated into any analysis of AcMPAG concentrations.

\section{Conclusion}

Based on the current information available, we can establish that UGT variants are not suitable for individualizing immunosuppressive therapy in transplant patients. There is a fundamental gap in knowledge related to the number of studies performed and their power 
to identify clinically meaningful associations. A recent report from the FDA Workshop on Pharmacodynamic and Pharmacogenomic Biomarkers in Solid Organ Transplantation did not include UGT variants among the potential biomarkers of immunosuppressive therapy [58]. UGT biomarkers were not regarded as potential promising biomarkers of overimmunosuppression in a recent review [59].

Acute rejection is probably a very complex phenotype that cannot be predicted by common genetic variation in one gene involved in the disposition of one of the drugs of immunosuppressive regimen. Another aspect that may further complicate examination of these relationships is that the transplanted organ is from a donor with a different genome than the recipient. Hopefully unbiased, comprehensive interrogation of the genomes of the patient and the donor could identify novel genes and pathways for further prospective investigation. To our knowledge, only candidate gene studies have been performed so far, providing inconclusive and/or conflicting results.

Even using intermediate phenotypes like pharmacokinetic parameters does not seem to be able to identify strong predictors of interpatient variability in patient exposure to pharmacologically or toxicologically active drugs or their metabolites. For example, MPA disposition might be influenced by a number of other variables, such as other immunosuppressives like tacrolimus, cyclosporine and corticosteroids, as well as interpatient variation in excretory pathways. Although therapeutic drug monitoring of MPA is not a routine procedure to individualize dosing and its role is debated [60,61], perhaps prospective validation of UGT variants (UGT1A9 $-275 \mathrm{~T}>\mathrm{A} /-2152 \mathrm{C}>\mathrm{T}$, or $-440 \mathrm{C}>\mathrm{T} /$ $-331 \mathrm{~T}>\mathrm{C}$, UGT1A $8-518 \mathrm{C}>\mathrm{G}(* 2))$ should be performed in a setting where the endpoint is the dose needed to achieve MPA levels within a predefined therapeutic window. In the context of such controlled studies, secondary endpoints of prevention of acute rejection could be used. From these studies, a combined UGT/MPA level biomarker could be prospectively tested for its role in avoiding acute rejection.

Many questions about the utilization of UGT SNPs as biomarkers in organ transplantation remain. What will be required to determine if UGT SNPs are a principal determinant of MPA pharmacokinetics and pharmacodynamics is to develop more sophisticated pharmacokinetic and pharmacodynamic models in adequately powered studies that incorporate these various elements in a large number of patients at different times post transplant. These models and important parameters then would need to be tested prospectively in transplant recipients. In addition, novel biology and candidate genes of transplantation outcomes should be discovered through genome-wide association studies, run within consortia to overcome the limitation of small and underpowered studies.

\section{References}

[1]. Gaston RS. Current and evolving immunosuppressive regimens in kidney transplantation. Am J Kidney Dis. 2006; 47:S3-S21. [PubMed: 16567239]

[2]. Halloran PF. Immunosuppressive drugs for kidney transplantation. NEJM. 2004; 351:2715-29. [PubMed: 15616206]

[3]. Glubb DM, Innocenti F. Mechanisms of genetic regulation in gene expression: examples from drug metabolizing enzymes and transporters. Wiley Interdiscip Rev Syst Biol Med. 2011; 3:299_ 313. [PubMed: 20865777]

[4]. Ramírez J, Ratain MJ, Innocenti F. Uridine 5'-diphospho-glucuronosyltransferase genetic polymorphisms and response to cancer chemotherapy. Future Oncol. 2010; 6:563-85. [PubMed: 20373870]

[5]. Desai AA, Innocenti F, Ratain MJ. UGT pharmacogenomics: implications for cancer risk and cancer therapeutics. Pharmacogenetics. 2003; 13:517-23. [PubMed: 12893990] 
[6]. Innocenti F, Liu W, Fackenthal D, et al. Single nucleotide polymorphism discovery and functional assessment of variation in the UDP-glucuronosyltransferase 2B7 gene. Pharmacogenet Genomics. 2008; 18:683-97. [PubMed: 18622261]

[7]. Strassburg CP, Barut A, Obermayer-Straub P, et al. Identification of cyclosporine A and tacrolimus glucuronidation in human liver and the gastrointestinal tract by a differentially expressed UDP-glucuronosyltransferase: UGT2B7. J Hepatol. 2001; 34:865-72. [PubMed: 11451170]

[8]. Laverdiere I, Caron P, Harvey M, et al. In vitro investigation of human UDPglucuronosyltransferase isoforms responsible for tacrolimus glucuronidation: predominant contribution of UGT1A4. Drug Metab Dispos. 2011; 39:1127-30. [PubMed: 21487055]

[9]. Cianco I. Review of major clinical trials with mycophenolate mofetil in renal transplantation. Transplantation. 2005; 80:S191-200. [PubMed: 16251852]

[10]. Health Resources and Services Administration. [accessed July 18, 2011] Organ procurement and transplant network. World Wide Web: http://optn.transplant.hrsa.gov/ar2009/109a_dh.pdf

[11]. Sanford M, Keating GM. Enteric coated mycophenolate sodium. A review of its use in the prevention of renal transplant rejection. Drugs. 2008; 68:2506-33.

[12]. Staatz CE, Tett SE. Clinical Pharmacokinetics and pharmacodynamics of mycophenolate in solid organ transplant recipients. Clin Pharmacokinet. 2007; 46:13-58. [PubMed: 17201457]

[13]. Shipkova M, Armstrong VM, Oellerich M, Weiland E. Acylglucuronide drug metabolites. Toxicological and analytical implications. Ther Drug Monit. 2003; 25:1-16. [PubMed: 12548138]

[14]. Knight SR, Morris PJ. Does evidence support the use of mycophenolate mofetil therapeutic drug monitoring in clinical practice. A systemic review. Transplantation. 2008; 85:1675-85. [PubMed: 18580456]

[15]. Rosso FC, Veras de Sandes LF, Mandia Sampaio FI, Park SI, Tedesco Silva H, Medina Pesatvav O. Clinical impact of polymorphisms of transplant proteins and enzymes involved in drug metabolism of immunosuppressive drugs. Transplant Proc. 2009; 41:1441-55. [PubMed: 19545654]

[16]. Kuypers DR, Naesens M, Vermiere S, Vanrenterghem Y. The impact of uridine diphosphateglucuronyltransferase 1A(UGT1A9) gene promoter region single-nucleotide polymorphisms $\mathrm{T}-275 \mathrm{~A}$ and $\mathrm{C}-2152 \mathrm{~T}$ on early mycophenolic acid dose-interval exposure in de novo renal allograft recipients. Clin Pharmacol Ther. 2005; 78:351-61. [PubMed: 16198654]

[17]. Kuypers DR, Dejonge H, Naesens M, et al. Current target ranges of mycophenolic acid exposure and drug related adverse events: a 5-year, open-label, prospective, clinical follow-up study in renal allograft recipients. Clin Ther. 2008; 30:673-83. [PubMed: 18498916]

[18]. Barraclough KA, Staatz CE, Elizabeth C, Isbel NM, Johnson DW. Therapeutic monitoring of mycophenolate in transplantation: is it justified? Curr Drug Metab. 2009; 10:179-87. [PubMed: 19275552]

[19]. vanGelder T, Silva HT, deFijter JW, Johan W, Budde K, Kuypers DR. Comparing mycophenolate mofetil regimens for de novo renal transplant recipients; the fixed-dose concentration-controlled trial. Transplantation. 2008; 86:1043-51. [PubMed: 18946341]

[20]. LeMeur Y, Buchler M, Thierry A, et al. Individualized mycophenolate dosing based on drug exposure significantly improves outcomes after renal transplantation. Am J Transplant. 2007; 7:2496-503. [PubMed: 17908276]

[21]. van Gelder T. Mycophenolate blood level monitoring: recent progress. Am J Transplant. 2009; 9:1495-9. [PubMed: 19519824]

[22]. deWinter BC, van Gelder T, Glander P, et al. Population pharmacokinetics of mycophenolic acid: a comparison between enteric-coated mycophenolate sodium and mycophenolate mofetil in renal transplant. Clin Pharmacokinet. 2008; 47:827-38. [PubMed: 19026038]

[23]. Kuypers DR, LeMeur Y, Cantarovich M, et al. Consensus report on the therapeutic drug monitoring of mycophenolic acid in solid organ transplantation. Clin J Am Soc Nephrol. 2010; 5:341-58. [PubMed: 20056756] 
[24]. Picard N, Ratanasavanh D, Premaud A, Le Meur Y, Marquest P. Identification of the UDPglucuronosyltransferase isoforms involved in mycophenolic acid phase II metabolism. Drug Metab Dispos. 2005; 33:139-46. [PubMed: 15470161]

[25]. Bernard O, Guillemette C. The main role of UGT1A9 in the hepatic metabolism of mycophenolic acid and the effects of naturally occurring variants. Drug Metab Dispos. 2004; 32:775-8. [PubMed: 15258099]

[26]. Bernard O, Tojcic J, Jorunalt J, Perusse L, Guillemette C. Influence of nonsynonymous polymorphisms of UGT1A8 and UGT2B7 metabolizing enzymes on the formation of phenolic and acyl glucuronides of mycophenolic acid. Drug Metab Dispos. 2006; 34:1539-45. [PubMed: 16790554]

[27]. Villenueve L, Girard H, Fortier LC, Gagne JF, Guillemette C. Novel functional polymorphisms in the UGT1A7 and UGT1A9 glucuronidating enzymes in Caucasian and African-American subjects and their impact on the metabolism of 7-ethyl-10-hydroxycamptothecin and flavopiridol anticancer drugs. J Pharmacol Exp Ther. 2003; 307:117-28. [PubMed: 12944498]

[28]. Duguay Y, Baar C, Skorpen F, Guillemette C. A novel functional polymorphisms in the uridine diphosphate-glucuronosyltransferase $2 \mathrm{~B} 7$ promoter with significant impact on promoter activity. Clin Pharmacol Ther. 2004; 75:223-33. [PubMed: 15001974]

[29]. Girard H, Court MH, Bernard O, et al. Identification of common polymorphisms in the promoter of the UGT1A9 gene: evidence that UGT1A9 protein and activity levels are strongly genetically controlled in the liver. Pharmacogenetics. 2004; 14:501-15. [PubMed: 15284532]

[30]. Sanchez Frutuoso AI, Maestro N, Calvo M, et al. The prevalence of uridine diphosphateglucuronosyltransferase 1A9 (UGT1A9) gene promoter region single-nucleotide polymorphisms $\mathrm{t}-275 \mathrm{~A}$ and $\mathrm{C}-2152 \mathrm{~T}$ and its influence on mycophenolic acid pharmacokinetics in stable renal transplant patients. Transplant Proc. 2009; 41:2313-6. [PubMed: 19715905]

[31]. van Schaik RH, van Agteren M, DeFijter JW, et al. UGT1A9-275T >A/-2152C >T polymorphisms correlate with low MPA exposure and acute rejection in MMF/tacrolimus-treated kidney transplant patients. Clin Pharmacol Ther. 2009; 86:319-27. [PubMed: 19494809]

[32]. Johnson LA, Oetting WS, Basu S, Prausa S, Matas A, Jacobson PA. Pharmacogenetic effect of the UGT polymorphisms on mycophenolate is modified by calcineurin inhibitors. Eur J Clin Pharmacol. 2008; 64:1047-56. [PubMed: 18568343]

[33]. Catteneo D, Perico N, Gaspari F, Gotti E, Remuzzi G. Glucocorticoids interfere with mycophenolate mofetil bioavailability in kidney transplantation. Kidney Int. 2002; 62:1060-7. [PubMed: 12164891]

[34]. Djebli N, Picard N, Rerolle JP, LeMeur Y, Marquet P. Influence of the UGT2B7 promoter region and exon 2 polymorphisms and comedications on acyl-MPAG production in vitro and in adult renal transplant patients. Pharmacogenet Genomics. 2007; 17:321-33. [PubMed: 17429314]

[35]. Kobayashi M, Satoh H, Kobayashi M, Tadano K, Takahashi Y, Hirano T. Cyclosporine A but not tacrolimus inhibits the biliary excretion of mycophenolic acid glucuronide possibly mediated by multidrug resistance-associated protein 2 in rats. J Pharmacol Exp Ther. 2004; 309:1029-35. [PubMed: 14978191]

[36]. Hesselink DA, Reinier N, VanHest RA, et al. Cyclosporine interacts with mycophenolic acid by inhibiting the multidrug resistance-associated protein 2. Am J Transplant. 2005; 5:978-94. [PubMed: 15816877]

[37]. Baldelli S, Merlini S, Perico N, et al. C-440/T-331C polymorphisms in the UGT1A9 gene affect the pharmacokinetics of mycophenolic acid in kidney transplantation. Pharmacogenomics. 2007; 8:1127-41. [PubMed: 17924828]

[38]. Picard N, Yee SW, Woliiard JB, et al. The role of organic anion-transporting polypeptides and their common genetic variants in mycophenolic acid pharmacokinetics. Clin Pharmacol Ther. 2010; 87:100-8. [PubMed: 19890249]

[39]. Gourishankar S, Houde I, Keown PA, et al. The CLEAR study: a 5-day, 3-g loading dose of mycophenolate mofetil versus standard 2-g dosing in renal transplantation. Clin J Am Soc Nephrol. 2010; 5:1282-9. [PubMed: 20498245]

[40]. Barraclough KA, Lee KJ, Staatz CE. Pharmacogenetic influences on mycophenolate therapy. Pharmacogenomics. 2010; 11:369-90. [PubMed: 20235793] 
[41]. Inoue K, Miura M, Satoh S, et al. Influence of 1A7 and UGT1A9 intronic I399 genetic polymorphisms on mycophenolic acid pharmacokinetics in Japanese renal transplant recipients. Ther Drug Monit. 2007; 29:299-304. [PubMed: 17529886]

[42]. Kagaya H, Inoue K, Miura M, et al. Influence of UGT1A8 and UGT2B7 genetic polymorphisms on mycophenolic acid pharmacokinetics in Japanese renal transplant recipients. Eur J Clin Pharmacol. 2007; 63:279-88. [PubMed: 17211619]

[43]. Zhang WX, Chen B, Jin Z, et al. Influence of uridine diphosphate (UDP)glucuronosyltransferases and $\mathrm{ABCC} 2$ genetic polymorphisms on the pharmacokinetics of mycophenolic acid and its metabolites in Chinese renal transplant recipients. Xenobiotica. 2008; 38:1422-36. [PubMed: 18946804]

[44]. Miura M, Kagay H, Satoh S, et al. Influence of drug transporters and UGT polymorphisms on pharmacokinetics of phenolic glucuronide metabolite of mycophenolic acid in Japanese transplant recipients. Ther Drug Monit. 2008; 30:559-64. [PubMed: 18695635]

[45]. Kuypers DR, Vanrenterghem Y, Squifflet JP, et al. Twelve month evaluation of clinical pharmacokinetics of total and free mycophenolic acid and its glucuronide metabolites in renal transplant recipients on low dose tacrolimus in combination with mycophenolate mofetil. Ther Drug Monit. 2003; 25:609-22. [PubMed: 14508385]

[46]. Shipkova M, Armstrong VW, Weber L, et al. Pharmacokinetics and protein adduct formation of the pharmacologically active acyl glucuronide metabolite of mycophenolic acid in pediatric renal transplant recipients. Ther Drug Monit. 2002; 24:390-9. [PubMed: 12021631]

[47]. Stracke S, Shipkova M, Mayer JL, et al. Pharmacokinetics and pharmacodynamics of mycophenolate sodium (EC-MPS) co-administered with cyclosporine in the early phase postkidney transplantation. Clin Transplant. 2011; 25:1-10.

[48]. van Agteren M, Armstrong VW, van Schaik RH, et al. AcylMPAG plasma concentrations and mycophenolic acid-related side effects in patients undergoing renal transplantation are not related to the UGT2B7-840G>A gene polymorphism. Ther Drug Monit. 2008; 30:439-44. [PubMed: 18641546]

[49]. Ting LS, Benoit-Biancamano MO, Bernard O, Riggs HW, Guillemette C, Ensom MH. Pharmacogenetic impact of UDP-glucuronosyltransferase metabolic pathway and multidrug resistance-associated protein 2 transport pathway on mycophenolic acid in thoracic transplant recipients: an exploratory study. Pharmacotherapy. 2010; 30:1097-108. [PubMed: 20973683]

[50]. Collins AJ, Foley RN, Herzog C, et al. Excerpts from the US renal data system 2009 annual data report. Transplantation. Am J Kidney Dis. 2010; 55:S281-94.

[51]. Christie JD, Edwards AB, Kucheyavaga AY, et al. The Registry of the International Society for Heart and Lung Transplantation: 27th official adult lung and heart-lung transplantation report. J Heart Lung Transplant. 2010; 29:1104-18. [PubMed: 20870165]

[52]. Michelon H, Konig J, Durrbach A, et al. SLCO1B1 genetic polymorphism influences mycophenolic acid tolerance in renal transplant recipients. Pharmacogenomics. 2010; 11:170313. [PubMed: 21142914]

[53]. Knoll GA, MacDonald I, Khan A, van Walraven C. Mycophenolate dose reduction and the risk of acute rejection after renal transplantation. J Am Soc Nephrol. 2003; 14:2381-6. [PubMed: 12937317]

[54]. Woillard JB, Rerolle JP, Picard N, et al. Risk of diarrhoea in a long-term cohort of renal transplant patients given mycophenolate mofetil: the significant role of the UGT1A8 2 variant allele. Br J Clin Pharmacol. 2010; 69:675-83. [PubMed: 20565459]

[55]. Yang JW, Lee PH, Hutchinson IV, Pravica V, Shah T, Min DI. Genetic polymorphisms of MRP2 and UGT2B7 and gastrointestinal symptoms in renal transplant recipients taking mycophenolic acid. Ther Drug Monit. 2009; 31:542-8. [PubMed: 19730281]

[56]. Betonico GN, Abbud-Filho M, Goloni-Bertollo EM, et al. Influence of UDPglucuronosyltransferase polymorphisms on mycophenolate mofetil-induced side effects in kidney transplant patients. Transplant Proc. 2008; 40:708-10. [PubMed: 18454993]

[57]. Prausa PE, Fukuda T, Maseck D, et al. UGT genotype may contribute to adverse events following medication with mycophenolate mofetil in pediatric kidney transplant recipients. Clin Pharmacol Ther. 2009; 85:495-500. [PubMed: 19225446] 
[58]. Gieser G, Harigaya H, Colangelo PM, Burckart G. Biomarkers in solid organ transplant. Clin Pharmacol Ther. 2011; 90:217-20. [PubMed: 21772300]

[59]. Badde K, Matz M, Durr M, Glander P. Biomarkers of over-immunosuppression. Clin Pharmacol Ther. 2011; 90:316-22. [PubMed: 21716278]

[60]. Byrne R, Yost SE, Kaplan B. Mycophenolate mofetil monitoring: is there evidence that it can improve outcomes. Clin Pharmacol Ther. 2011; 90:204-6. [PubMed: 21772295]

[61]. van Gelder T. Therapeutic drug monitoring for mycophenolic acid is value for little money. Clin Pharmacol Ther. 2011; 90:203-4. [PubMed: 21772294] 
Table 1

MPA clinical pharmacogenetic and pharmacokinetic studies ${ }^{a}$.

\begin{tabular}{|c|c|c|}
\hline UGT SNP (reference number) & Number/transplant population/ethnicity/other immunosuppression & Significant association/results \\
\hline \multirow[t]{5}{*}{$1 \mathrm{~A} 9-275 \mathrm{~T}>\mathrm{A} /-2152 \mathrm{C}>\mathrm{T}[16]$} & 95 kidney & $\begin{array}{l}\text { Lower MPA AUC 0-12 h } \\
\text { (day7)with } 2 \text { g/day only }\end{array}$ \\
\hline & Caucasian & $\begin{array}{l}\text { Lower MPA AUC } 6-12 \mathrm{~h} \text { with } 2 \\
\text { g/day only }\end{array}$ \\
\hline & Tacrolimus and steroids & Lower $\mathrm{C} 0$ with $2 \mathrm{~g} /$ day only \\
\hline & & Shorter Tmax with $2 \mathrm{~g} /$ day only \\
\hline & & Higher $\mathrm{Cl} / \mathrm{F}$ with $2 \mathrm{~g} /$ day only \\
\hline \multirow[t]{3}{*}{$1 \mathrm{~A} 9-275 \mathrm{~T}>\mathrm{A} /-2152 \mathrm{C}>\mathrm{T}[31]$} & 338 kidney & $\begin{array}{l}\text { Lower MPA AUC/D } 0-12 \mathrm{~h} \text { (day } \\
3 \text { and } 1 \text { year) with tacrolimus only }\end{array}$ \\
\hline & $88 \%$ Caucasian & Lower percent difference in MPA \\
\hline & Tacrolimus or cyclosporine & $\begin{array}{l}\text { AUC 0-12 h/D (over } 1 \text { year) with } \\
\text { tacrolimus only }\end{array}$ \\
\hline \multirow[t]{3}{*}{$1 \mathrm{~A} 9-275 \mathrm{~T}>\mathrm{A} /-2152 \mathrm{C}>\mathrm{T}[32]$} & 117 kidney and/or pancreas & Lower C0/D with cyclosporine \\
\hline & $90 \%$ Caucasian & \\
\hline & Tacrolimus or cyclosporine & \\
\hline \multirow[t]{2}{*}{$1 \mathrm{~A} 9-275 \mathrm{~T}>\mathrm{A} /-2152 \mathrm{C}>\mathrm{T}[17]$} & 100 kidneys & Lower $\%$ of patients within target \\
\hline & Tacrolimus and steroids & AUC 0-12 h range \\
\hline \multirow[t]{3}{*}{$1 \mathrm{~A} 9-275 \mathrm{~T}>\mathrm{A} /-2152 \mathrm{C}>\mathrm{T}[30]$} & 30 kidney & Lower AUC $0-12 \mathrm{~h}$ \\
\hline & Caucasian & Lower AUC $0-6 \mathrm{~h}$ \\
\hline & Tacrolimus & Lower AUC 6-12 h \\
\hline \multirow[t]{2}{*}{$1 \mathrm{~A} 9-440 \mathrm{C}>\mathrm{T}[38]$} & 185 kidney & Shorter Tmax \\
\hline & Tacrolimus or sirolimus or cyclosporine and steroids & \\
\hline \multirow[t]{3}{*}{$1 \mathrm{~A} 9-440 \mathrm{C}>\mathrm{T}[37]$} & 40 kidney & Lower AUC $0-12 \mathrm{~h} / \mathrm{D}$ \\
\hline & Caucasian & \\
\hline & Cyclosporine & \\
\hline \multirow[t]{3}{*}{$1 \mathrm{~A} 9-331 \mathrm{~T}>\mathrm{C}[37]$} & 40 kidneys & Lower AUC $0-12 \mathrm{~h} / \mathrm{D}$ \\
\hline & Caucasian & \\
\hline & Cyclosporine & \\
\hline \multirow[t]{3}{*}{$1 \mathrm{~A} 9-98 \mathrm{~T}>\mathrm{C}(* 3)[31]$} & 338 kidney & Higher AUC 0-12 h \\
\hline & Tacrolimus or cyclosporine & Higher \% difference in AUC 0- \\
\hline & $88 \%$ Caucasian & $\begin{array}{l}12 \mathrm{~h} / \mathrm{D} \text { (over } 1 \text { year) with } \\
\text { tacrolimus and cyclosporine }\end{array}$ \\
\hline \multirow[t]{3}{*}{$1 \mathrm{~A} 9-98 \mathrm{~T}>\mathrm{C}(* 3)[16]$} & 95 kidney & $\begin{array}{l}\text { Higher AUC } 0-12 \mathrm{~h} \text { with } 1 \mathrm{~g} / \text { day } \\
\text { only }\end{array}$ \\
\hline & Caucasian & Higher AUC 6-12 h \\
\hline & Tacrolimus or steroids & \\
\hline \multirow[t]{2}{*}{$1 \mathrm{~A} 9-98 \mathrm{~T}>\mathrm{C}(* 3)[38]$} & 185 kidney & Higher Cmax/D \\
\hline & Tacrolimus or sirolimus or cyclosporine and steroids & With tacrolimus or sirolimus \\
\hline \multirow[t]{3}{*}{$1 \mathrm{~A} 8-518 \mathrm{C}>\mathrm{G}(* 2)[32]$} & 117 kidney & \multirow{3}{*}{$\begin{array}{l}\text { Higher } \mathrm{C} 0 / \mathrm{D} / \mathrm{T} \text { (over } 1 \text { year) with } \\
\text { tacrolimus }\end{array}$} \\
\hline & $90 \%$ Caucasian & \\
\hline & Tacrolimus or cyclosporine & \\
\hline $1 \mathrm{~A} 8-518 \mathrm{C}>\mathrm{G}(* 2)[31]$ & 338 kidney & $\begin{array}{l}\text { Higher AUC } 0-12 \mathrm{~h} \text { (over } 1 \text { year) } \\
\text { with cyclosporine }\end{array}$ \\
\hline
\end{tabular}




\begin{tabular}{|c|c|c|}
\hline UGT SNP (reference number) & Number/transplant population/ethnicity/other immunosuppression & Significant association/results \\
\hline & $88 \%$ Caucasian & \\
\hline & Tacrolimus or cyclosporine and steroids & \\
\hline \multirow[t]{4}{*}{$1 \mathrm{~A} 8-518 \mathrm{C}>\mathrm{G}(* 2)[38]$} & 185 kidney & Lower $\mathrm{C} 0 / \mathrm{D}$ \\
\hline & Tacrolimus or sirolimus or cyclosporine and steroids & Lower Cmax/D \\
\hline & & Lower AUC $0-12 \mathrm{~h} / \mathrm{D}$ \\
\hline & & With tacrolimus or sirolimus \\
\hline \multirow[t]{3}{*}{$2 \mathrm{~B} 7-802 \mathrm{C}>\mathrm{T}[37]$} & 40 kidney & Higher Cmax/D \\
\hline & Caucasian & \\
\hline & Cyclosporine & \\
\hline \multirow[t]{3}{*}{$2 \mathrm{~B} 7-842 \mathrm{G}>\mathrm{T}[34]$} & 92 kidney & $\begin{array}{l}\text { Higher AcMPAG AUC 0-9 h/D } \\
\text { (1 month) with sirolimus }\end{array}$ \\
\hline & Tacrolimus or cyclosporine or sirolimus and steroids & Higher AcMPAG AUC 0-9 h/D \\
\hline & & (3 month) with sirolimus \\
\hline \multirow[t]{2}{*}{$2 \mathrm{~B} 7-802 \mathrm{C}>\mathrm{T}[49]$} & 68 thoracic & Higher AcMPAG AUC $0-12 \mathrm{~h}$ \\
\hline & Tacrolimus or cyclosporine & Higher AcMPAG/MPA ratio \\
\hline \multirow[t]{2}{*}{$2 \mathrm{~B} 7-138 \mathrm{~A}(* 2)[49]$} & 68 thoracic & Higher AcMPAG AUC $0-12 \mathrm{~h}$ \\
\hline & Tacrolimus or cyclosporine & Higher AcMPAG/MPA ratio \\
\hline
\end{tabular}

MPA = mycophenolic acid or mycophenolate AcMPAG = acyl glucuronide; $\mathrm{MPAG}=$ mycophenolic acid glucuronide $; \mathrm{AUC}=$ area under the concentration; $\mathrm{Cmax}=$ maximum concentration; $\mathrm{C} 0=$ trough concentration; $\mathrm{Tmax}=$ time to maximum concentration; $\mathrm{CL}=$ clearance; $\mathrm{F}=$ Bioavailability; $\mathrm{D}=$ dose.

${ }^{a}$ This table lists only studies that reported a statistically significant association between UGT polymorphisms and pharmacokinetic parameters. 
Table 2

MPA-UGT pharmacogenetics and outcomes.

\begin{tabular}{|c|c|c|c|c|c|}
\hline Reference number & SNP/objective & Study design & Study population & Clinical outcome(s) & Results \\
\hline [49] & $\begin{array}{l}\text { To assess the link } \\
\text { between UGT and } \\
\text { ABCC2 } \\
\text { polymorphisms to } \\
\text { MPA } \\
\text { pharmacokinetics and } \\
\text { clinical outcomes }\end{array}$ & Cross-sectional & $\begin{array}{l}68 \text { mostly Caucasian } \\
\text { lung or heart transplant } \\
\text { recipients }\end{array}$ & $\begin{array}{l}\text { GI toxicities } \\
\text { Leukopenia } \\
\text { Thrombocytopenia } \\
\text { Anemia } \\
\text { Infections } \\
\text { Biopsy-proven acute } \\
\text { rejection episodes } \\
\text { (BPAR) }\end{array}$ & $\begin{array}{l}\text { Occurrences of } \\
\text { rejection and } \\
\text { infection associated } \\
\text { with an AcMPAG } \\
\text { AUC }>50 \mu \mathrm{g} \cdot \mathrm{h} / \mathrm{ml} \text {. } \\
\text { Infections, } \\
\text { leukopenia, and } \\
\text { anemia associated } \\
\text { with } \\
\text { AcMPAG:MPA>2 }\end{array}$ \\
\hline [56] & $\begin{array}{l}\text { To examine the } \\
\text { correlation between } \\
\text { UGT1A8 } \\
\text { polymorphisms and } \\
\text { MPA side effects }\end{array}$ & Retrospective & $\begin{array}{l}74 \text { kidney transplant } \\
\text { patients on MMF for at } \\
\text { least } 30 \text { days }\end{array}$ & MPA adverse effects & $\begin{array}{l}\text { Greater occurrence } \\
\text { of infections among } \\
\text { individuals } \\
\text { receiving MMF } 2 \\
\text { g/d and carrying the } \\
\text { UGT1A8 277A } \\
\text { polymorphism, } \\
\text { haplotype } \\
\text { UGT1A8H5 or } \\
\text { diplotype } \\
\text { UGT1A8H2/H5. }\end{array}$ \\
\hline [54] & $\begin{array}{l}\text { To investigate the } \\
\text { relationship between } \\
\text { UGT polymorphisms, } \\
\text { ABCC2 } \\
\text { polymorphisms, and } \\
\text { co-administered } \\
\text { immunosuppressants } \\
\text { with MPA GI side } \\
\text { effects }\end{array}$ & Retrospective cohort & 256 kidney transplants & $\begin{array}{l}\text { Diarrhea } \\
\text { Global incidence of } \\
\text { all Gastrointestinal } \\
\text { adverse effects }\end{array}$ & $\begin{array}{l}\text { Non-carriers of the } \\
\text { UGT1A } 8 * 2 \text { allele } \\
\text { had a higher risk of } \\
\text { diarrhea than } \\
\text { carriers. }\end{array}$ \\
\hline [55] & $\begin{array}{l}\text { To determine the } \\
\text { relationship between } \\
\text { MRP2 and UGT2B7 } \\
\text { polymorphisms with } \\
\text { GI adverse events } \\
\text { severity }\end{array}$ & Prospective & $\begin{array}{l}67 \text { kidney transplant } \\
\text { recipients receiving } \\
\text { MMF or enteric-coated } \\
\text { MPA sodium Country: } \\
\text { United States }\end{array}$ & $\begin{array}{l}\text { GI symptom rating } \\
\text { scale (GSRS) } \\
\text { Diarrhea subscale of } \\
\text { GSRS }\end{array}$ & $\begin{array}{l}\text { Homozygous wild } \\
\text { type UGT2B7 } \\
\text { showed } \\
\text { significantly higher } \\
\text { mean GSRS scores } \\
\text { compared to variant } \\
\text { UGT2B7. }\end{array}$ \\
\hline [48] & $\begin{array}{l}\text { To examine the } \\
\text { impact of UGT2B7 } \\
\text { polymorphisms on } \\
\text { AcMPAG plasma } \\
\text { concentrations. To } \\
\text { investigate the } \\
\text { correlation of } \\
\text { AcMPAG } \\
\text { concentrations with } \\
\text { MPA related side } \\
\text { effect. }\end{array}$ & Open-label RCT & 332 renal transplants & Diarrhea Leukopenia & $\begin{array}{l}\text { No association } \\
\text { between diarrhea or } \\
\text { leukopenia with } \\
\text { AcMPAG } \\
\text { concentrations. }\end{array}$ \\
\hline [57] & $\begin{array}{l}\text { To study the } \\
\text { incidence of UGT } \\
\text { polymorphisms in } \\
\text { MPA related } \\
\text { leukopenia and } \\
\text { diarrhea. }\end{array}$ & Case-control & $\begin{array}{l}16 \text { pediatric kidney } \\
\text { transplant patients that } \\
\text { experience MPA- } \\
\text { related leukopenia and } \\
\text { diarrhea }\end{array}$ & $\begin{array}{l}\text { Diarrhea } \\
\text { Leukopenia }\end{array}$ & $\begin{array}{l}\text { Greater frequency } \\
\text { of occurrence of } \\
\text { UGT1A9-331 } \\
\text { SNP is evident in } \\
\text { the adverse event } \\
\text { group as compared } \\
\text { to the control } \\
\text { group. }\end{array}$ \\
\hline [31] & $\begin{array}{l}\text { To explore the } \\
\text { association between } \\
\text { UGT1A8, UGT1A9, } \\
\text { UGT2B7, and MRP2 }\end{array}$ & Prospective cohort & $\begin{array}{l}338 \text { kidney transplant } \\
\text { patients receiving } \\
\text { MMF }\end{array}$ & BPAR & $\begin{array}{l}\text { UGT1A9 } \\
-275 \mathrm{~T}>\text { Aand/or } \\
-2152 \mathrm{C}>\mathrm{T} \\
\text { polymorphism }\end{array}$ \\
\hline
\end{tabular}




\begin{tabular}{|c|c|c|c|c|c|}
\hline Reference number & SNP/objective & Study design & Study population & Clinical outcome(s) & Results \\
\hline & $\begin{array}{l}\text { polymorphisms with } \\
\text { MPA exposure and } \\
\text { acute organ rejection }\end{array}$ & & & & $\begin{array}{l}\text { associated with } \\
\text { acute rejection in } \\
\text { patients receiving } \\
\text { fixed dose MPA } \\
\text { with concomitant } \\
\text { tacrolimus }\end{array}$ \\
\hline \multirow[t]{2}{*}{ [52] } & $\begin{array}{l}\text { To examine the } \\
\text { association of } \\
\text { ABCB1, ABCC2, } \\
\text { UGT2B7, UGT1A9, } \\
\text { SLCO1B1, SLCO1B3 } \\
\text { and IMPDH1 } \\
\text { polymorphisms with } \\
\text { response to MPA }\end{array}$ & Prospective cohort & $\begin{array}{l}218 \text { kidney transplant } \\
\text { recipients who } \\
\text { received MMF at a } \\
\text { fixed dose of } 2 \mathrm{~g} / \text { day }\end{array}$ & BPAR & $\begin{array}{l}\text { No associations } \\
\text { found between } \\
\text { other } \\
\text { polymorphisms and } \\
\text { ADRs. No } \\
\text { association found } \\
\text { between } \\
\text { polymorphisms and } \\
\text { acute rejections. }\end{array}$ \\
\hline & & & & $\begin{array}{l}\text { First occurrence of } \\
\text { leukopenia, anemia, } \\
\text { thrombocytopenia, } \\
\text { diarrhea, nausea/ } \\
\text { vomiting or infection } \\
\text { observed during 1st } \\
\text { year post- } \\
\text { transplantation }\end{array}$ & $\begin{array}{l}\text { SLCO1B } 1 * 5 \text { allele } \\
\text { found to have } \\
\text { protective effect on } \\
\text { MPA adverse } \\
\text { effects. }\end{array}$ \\
\hline
\end{tabular}

MPA = mycophenolic acid or mycophenolate AcMPAG = Acyl glucuronide; $\mathrm{MMF}=$ mycophenolate mofetil; $\mathrm{AUC}=$ area under the concentration time curve; BPAR = biopsy proven acute rejection. 